9.Suo $M$, Sun $Y$, Yang $H$, Ji J, He $Y$, Dong L, Wang $Y$, Zhang $Y$, Zhang $Y$ and Hao M. miR-183-5p suppressed the invasion and migration of HTR-8/ SVneo trophoblast cells partly via targeting MMP-9 in preeclampsia. Biosci Rep. 2020;40. DOI: 10.1042/ BSR20192575

10. Han N, Xu H, Yu N, Wu Y and Yu L. MiR-203a$3 p$ inhibits retinal angiogenesis and alleviates proliferative diabetic retinopathy in oxygen-induced retinopathy (OIR) rat model via targeting VEGFA and HIF-1alpha. Clin Exp Pharmacol Physiol. 2020;47:8594. DOl: 10.1111/1440-1681.13163
11.Sela S, Natanson-Yaron S, Zcharia E, Vlodavsky I, Yagel S and Keshet E. Local retention versus systemic release of soluble VEGF receptor-1 are mediated by heparin-binding and regulated by heparanase. Circulation research. 2011;108:106370. DOI: 10.1161/CIRCRESAHA.110.239665

12. Moore $\mathrm{KH}$, Chapman $\mathrm{H}$ and George EM. Unfractionated heparin displaces sFlt-1 from the placental extracellular matrix. Biol Sex Differ. 2020;11:34.DOI: 10.1186/s13293-020-00311-w

\title{
Clinical Aspects of Hypertension in Pregnancy: Complications of Pregnancy as Predictors of Cardiovascular Risk
}

\author{
BIANCA DAVIDSON \& ERIKA JONES \\ University of Cape Town, \\ Cape Town, South Africa.
}

DOI:10.30824/2106-6

Hypertension during pregnancy is an independent risk factor for cardiovascular events. This has clearly been documented in multiple studies ${ }^{1-3}$. Recently, numerous studies have contributed to evidence on the degree of added risk these women experience.

The CALIBER study ${ }^{4}$ fills this gap and has reported an excess of cardiovascular complications in women at a younger age. The median age that the complications occur is less than forty years, which is below the age that traditional annual screening for hypertension and other cardiovascular risk factors is initiated. Therefore, to initiate screening at forty is too late. The data from this study were discussed by Lucy Chappell, at the ESH-ISH 2021 Joint Meeting in April 2021. As recommended
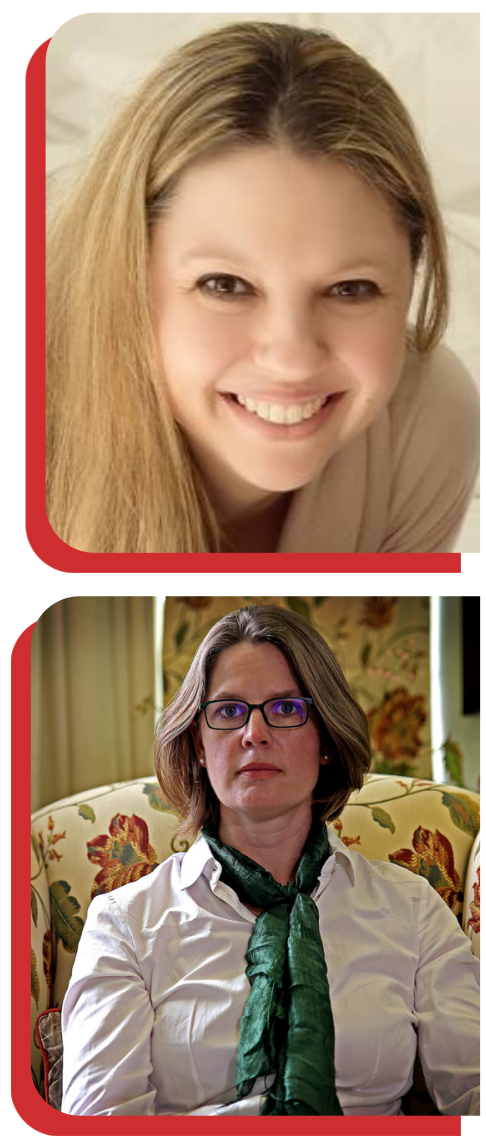

in the ISH Global Hypertension Guidance ${ }^{5}$, it is essential that these women are monitored from a much earlier age.

It has been observed that clinical trials are not a real life setting and the subjects enrolled in these trials are highly selected, excluding the vast majority of patients. The CALIBER data are real world data from a large cohort, with almost 1.9 million pregnancies assessed. Furthermore, the CALIBER population appears to be a realistic representation of pregnant women as demonstrated by similarities to previous populations, with similar risk factors.

A cardiovascular event occurred in 18624 women within a median follow-up of 9.25 years. The majority (65\%) of which occurred in women 
under 40 years. The proportion of cardiovascular events in the pre-eclamptic patients was $2.77 \%$, as opposed to half that (1.4\%) in non-pre-eclamptic patients. Pre-eclampsia gave a hazards ratio of 1.69 (Cl 1.57-1.81) for a first cardiovascular incident and pre-eclampsia resulting in a preterm delivery resulted, in a much higher hazards ratio of 5.63 (5.1-6.26). While the risk was lower in those who had hypertension (but not pre-eclampsia), there remained a strong association with hypertension during pregnancy and the development of chronic hypertension and early cardiovascular events.

Adjusting for persistent hypertension after preeclampsia attenuated the risk for cardiovascular events but did not negate it. This means that, independent of the subsequent development of chronic hypertension, pre-eclampsia was associated with an increased risk of cardiovascular events.

Following up on women who have had an episode of hypertension in a pregnancy could improve the lives for not only themselves and their families but the communities in which they live, as they are a young population who contribute to the work force and future generations. Women with hypertension during their pregnancies have a high risk of death at an early age from cardiovascular events. Furthermore, morbidity associated with the maternal hypertensive disorders amounts to 24.2/100 000 DALYs $^{6}$.

After a follow up of less than 10 years, women with hypertension during their pregnancy presented with first cardiovascular events, $65 \%$ of whom were under 40 years of age. Hypertension during their pregnancy was an independent risk factor, over and above recognised cardiovascular risk factors. Pre-eclampsia, in particular those with a preterm delivery, increases the risk for a cardiovascular event.
These women should be screened for hypertension after any form of hypertension during pregnancy and followed up closely to mitigate the risk for future cardiovascular disease. This policy is promoted in the ISH guidelines and needs to be adopted internationally. Hypertension during pregnancy needs to be recognised as an independent risk factor for cardiovascular events and needs to be included in future risk stratification scores.

\section{References:}

1.Groenhof TKJ, Zoet GA, Franx A, Gansevoort RT, Bots ML, Groen H, Lely AT and Group P. Trajectory of cardiovascular risk factors after hypertensive disorders of pregnancy: an argument for followup. Hypertension. 2019;73:171-178. DOI: 10.1161/ HYPERTENSIONAHA.118.11726

2.Brown MC, Best KE, Pearce MS, Waugh J, Robson $\mathrm{SC}$ and Bell R. Cardiovascular disease risk in women with pre-eclampsia: systematic review and metaanalysis. Eur J Epidemiol. 2013;28:1-19. DOI: 10.1007/s10654-013-9762-6

3.Drost JT, Arpaci G, Ottervanger JP, de Boer MJ, van Eyck J, van der Schouw YT and Maas AH. Cardiovascular risk factors in women 10 years post early preeclampsia: the Preeclampsia Risk EValuation in FEMales study (PREVFEM). Eur J Prev Cardiol. 2012;19:1138-44. DOI: 10.1177/1741826711421079

4.Leon LJ, McCarthy FP, Direk K, Gonzalez-Izquierdo A, Prieto-Merino D, Casas JP and Chappell L. Preeclampsia and cardiovascular disease in a large UK pregnancy cohort of linked electronic health records: A CALIBER study. Circulation. 2019;140:1050-1060. DOI: 10.1161/CIRCULATIONAHA.118.038080

5.Unger T, Borghi C, Charchar F, Khan NA, Poulter NR, Prabhakaran D, Ramirez A, Schlaich M, Stergiou GS, Tomaszewski M, Wainford RD, Williams $B$ and Schutte AE. 2020 International Society of Hypertension global hypertension practice guidelines. J Hypertens. 2020;38:982-1004. DOI: 10.1097/HJH.0000000000002453

6.Cooper C. Global, regional, and national disabilityadjusted life-years (DALY) for 359 diseases and injuries and health life expectancy (HALE) for 195 countries and territories, 1990-2017: a systematic analysis for the Global Burden of Disease Study 2017. The Lancet. 2018;392:1859-1922. DOI: $10.1016 / 50140-6736(18) 32335-3$ 